\title{
A Conversation with Adam Kepecs
}

\author{
Interviewer: SÉBastien Thuault \\ Senior Editor, Nature Neuroscience
}

Adam Kepecs is a Professor at Cold Spring Harbor Laboratory.

Sébastien Thuault: Why don't you tell us about some of your research interests, some of the projects going on in your lab?

Dr. Kepecs: I'm very interested in how brains make decisions. I'm interested in the computational mechanism: what makes brains able to do feats that computers, even in the age of amazing AI [artificial intelligence], cannot do? On the other hand, I'm also very interested in the cellular mechanisms at the level of neural circuits: Where's the "magic" in brains? What about them, in terms of the biological machinery, makes them able to do these things?

Sébastien Thuault: What kind of aspects of behavior do you study in the lab?

Dr. Kepecs: We have a range of studies. For instance, one of the topics is "decision confidence." We're interested in the neural processes behind decision confidence and try to study this in rodents so that we have the chance to go down to the level of neural circuits.

Sébastien Thuault: How do you define "confidence"? Obviously, it's something that we use when we make decisions on a daily basis, but you study that in animals. I imagine that it needs to be properly defined so that it can be interrogated in the model systems?

Dr. Kepecs: Exactly. Your question strikes at the heart of the problem, which is that when we're dealing with a highlevel cognitive concept, we need to be very careful and operationalize it and formulate a whole way in which we can make these claims. The first set of studies that we've actually done was with humans. We tried to relate the notion of statistical confidence, which can be easily defined as the probability that an outcome, an option, is going to be correct given the available evidence. That's a formal statement, and we try to relate it to how humans respond when they're asked about their confidence. That established a framework for us to lay the groundwork for most of the actual animal work in the lab.

Sébastien Thuault: What did you find in that study in humans that laid the ground for the research after that?

Dr. Kepecs: We found that when asked in a way where we could actually define the right answer and provide evidence in a graded way-we knew exactly what kind of evidence we provided for each decision - then their confidence reports actually matched pretty much what statistics told you. People are basically using some sort of statistical machinery that enables them to report their feeling of confidence.

Sébastien Thuault: How do you then translate this in the laboratory for the mechanisms in animal models?

Dr. Kepecs: We need to first consider the reason we have subjective confidence. It is because having the ability to know your confidence is going to make you be a better organism, one that's more adaptive and able to survive. It's really a fundamental ability to essentially take the statistics of the environment, the uncertainty, summarize it, and use it for your own behavior. That's what confidence is. Any organism with this ability is going to outperform organisms that do not have it. This suggests that we don't need to approach it from the level of feelings, but we can approach it as a question of behavioral incentives, and ask how having confidence is going to make you better at a particular task than not having confidence.

We created a version of a simple two-choice decision behavior. Two-choice decisions are something that we, and others, are studying in rodents now. We can do this with olfactory stimuli or auditory stimuli. The animal receives, say, an odor. Typically, we mix these up because rodents are so good at this that if you ask them to decide between a pair of stereoisomers, they're going to be perfect in their answers. Perfect, that's good, but then it's not interesting because they're not uncertain about their answers. So in order to dial in the uncertainty, we mix up odors in different proportions and deliver them at a central port. Rats get an odor, and we pair one with a reward. If they get odor A and they go to the left, then they're going to get a drop of water, and if they get odor B and they go to the right, then they're going to get a reward. Then we mix odors in different proportions and they have to figure out what's the dominant odor. That's a basic scenario. That's the classic psychophysical setup.

On top of it, we create an investment decision. Instead of delivering the reward immediately when it's available, we delay the reward and do some according to a random

(C) 2018 Kepecs. This article is distributed under the terms of the Creative Commons Attribution-NonCommercial License, which permits reuse and redistribution, except for commercial purposes, provided that the original author and source are credited. 
schedule, so then the animal has to wait around and invest different amounts of time in order to get rewarded. And we can measure the amount of time they are willing to wait after the decision.

Sébastien Thuault: That's very ingenious. How do you come up with this idea to test this in the animal model? Did you try other things?

Dr. Kepecs: We had a previous version of it that was a betting behavior where they had to restart. But we really started from a serendipitous observation about orbitofrontal cortex neurons. We recorded these neurons in a perceptual decision task without any confidence-guided decision. We were thinking about these issues and our minds were ready, but we didn't really know what to expect. Then firing patterns of some of these neurons were strange and these called out for an explanation. We formulated a computational model to explain it, and that's when the realization came: that those very strange firing patterns could be explained if these neurons were representing confidence. We then retraced our steps to figure out, how do we ask our rats to express this confidence?

Sébastien Thuault: What are the main findings in these studies? You have the behavior and you find some correlation with what you define as confidence, but you also performed some recording.

Dr. Kepecs: We're recording in this brain area called lateral orbitofrontal cortex (OFC). It's a frontal area that has some homologs in primates as well. This is an area that's involved in "valuation": inferring the values of different options in the world and outcomes. This area should represent confidence when the world is ambiguous because that's going to be your best bet to figure out what the value of different options is. Indeed, we see different kinds of neurons functionally, and postdecision many of these neurons report confidence. Some of these neurons are correlated with the time investment behavior, so we can actually use the neural activity to predict how long the animal's going to invest in a particular decision.

If you're a psychologist and thinking about confidence you often think about it as a metacognitive ability. The idea is that confidence relies on a monitoring process and in this sense it's meta. And this would also imply that the confidence representation ought to be generalized and not specific to one type of sensory stimulation. One of the very recent studies we've done is to record these neurons in a dual task where we have auditory and olfactory decisions and can show that the same neurons represent confidence about both of these decision types.

We can also inactivate this brain area. One of the advantages of working with rats is you can do a lot of invasive experiments as well, where we can really interrogate the neural mechanisms. We can turn off this region, the OFC. By turning off the area, what we found is that the decisions themselves weren't impacted at all, which makes sense; these are perceptual decisions. But time investment became random. It's not that animals spent more or less time waiting for a reward, but that time spent was no longer predictive of accuracy so they were essentially not as optimal in investing time.

Sébastien Thuault: It's as if they couldn't have any confidence in what they thought. I imagine you saw different types of electrophysical behavior. When you were recording in the OFC, you saw those neurons that tracked confidence. Did you find other kinds of responses there?

Dr. Kepecs: There's lots of other kinds of responses. That's one of the challenges that we face in cortical physiology, especially in frontal cortex. One thing we can do is we can manipulate different contingencies. For example, we can change reward size and then ask the question: Do these neurons vary with reward size as well? One of the observations we made is that there are neurons that specialize in confidence and they don't care about reward, there are neurons that specialize in reward size and they don't care about confidence, and there are neurons that integrate the two and always do so sort of the right way so that they represent either high value or low value.

These are the functional classes. They also often have different time courses. One of the things we are thinking about now is how to connect these differences in the functional types to the neural cell types. That's one of the critical challenges that we face in systems in neuroscience today is to relate the incredible diversity, and also exquisite precision, of different cell types in cortex to behavior.

Sébastien Thuault: I know you're very much interested in cell types, so what would be the next step?

Dr. Kepecs: We've gone through an incredible revolution in neuroscience and it's so exciting to be able to do experiments that we couldn't have imagined even a few years ago. We have a number of different ways in which we're trying to get access to the cell types. We use this method called optogenetic tagging: We put channelrhodopsin-a light-activatable channel-into specific projection neuron types, neurons that target certain areas and not others. We know that some of these neuron types sort themselves out so one type goes to one brain region. Along with our electrodes, we put in a tiny optical fiber and we try to activate them - not to change behavior but to use it as a beacon to figure out what cell type it is. This way we're trying to figure out what do different cell types do.

Sébastien Thuault: Do you have an interest in interneurons? Do you already have a few pieces of data that illustrate what could be the function of these in this region?

Dr. Kepecs: We're just starting in OFC with inhibitory neurons, partly because we did all this work in rats and in rats it's a little harder to genetically target cell types. But we've done a lot of work on genetic cell types in mice. Those studies are not about confidence, but they are related to frontal cortical questions and fundamentally trying to address issues that are easier to access in mice-for instance, about the functions of these different cell types. We learned that some of the major cell types, the cardinal inhibitor neuron types, have very different behavioral functions. PV [parvalbumin], somatostatin, and VIP 
[vasoactive intestinal peptide] types of neurons, which probably also have their own subtypes, do respond in very unique ways. We're trying to figure out the principles of this.

Sébastien Thuault: You see this diversity of cellular behavior in this region. One of the questions is how these neurons interact and what kind of information is integrated and what kind of circuit motifs are important to process the information. How do you think this can be best addressed? You have a theoretical background. Is this something that could be used to generate a hypothesis?

Dr. Kepecs: I think there are a lot of hypotheses. What's changed overall is all these new technologies that truly allow us to interrogate the brain. Until quite recently, when you were interested in cell types, you could only use reduced preparations. You could take neurons out of the brain, you could look at their anatomy or you could target a neuron in vitro. What really changed is that now you can do all of that at a much greater throughput but in addition interrogate these in a behaving animal. That's what gives you access to whole new dimensions in terms of what their functions might be.

The issue this speaks to, really, is the debate that's still ongoing about what's the correct way to categorize cell types. With all these sequencing technologies - RNA-seq, where you can have incredible information about single cells - and anatomical mapping projects, you have a lot of hypotheses about how to categorize cell types. I would argue that we also need to include functional criteria because ultimately neurons of a given cell type should functionally behave in similar ways.

Sébastien Thuault: You have also a strong interest in neuromodulation. Decision-making is going to really depend on context, on external variables that influence brain states and things like this. Is this also something you're exploring?
Dr. Kepecs: Neuromodulation is something I'm very excited about. Neuromodulators basically sit at the bottom of the brain and project across many brain regions, and that makes them unique in their ability to reconfigure circuits. There's been a lot of computational hypotheses put forward about these, so those strongly influence our work. Again, there are a lot of new tools with which we are finally able to interrogate these systems, so that's something that's very exciting for us. In addition, some of our work is actually connecting with inhibitory neurons because we think they might actually exert some of their postsynaptic effects through specific subtypes of neurons.

Sébastien Thuault: I wanted to ask you about how you see this kind of work being important in the context of the clinical realm. Can it be important for translational neuroscience? What are your thoughts on this? Is this something that you're interested in developing in your lab?

Dr. Kepecs: I'm very interested in biological psychiatry. We started a number of different studies in this area. The basic challenge for psychiatry is that the symptoms are very subjective. We know that they derive from something going wrong in the brain, but it's very difficult to address subjective symptoms in a rigorous scientific way. I think neuroscience is really faced with the challenge of how to connect our studies to something that's useful for psychiatrists. Some of our own work in cognition is useful because in order for us to establish that, operationally, rats can express their confidence behaviorally, we came up with a quantitative approach that we can use for humans as well. And we can create metrics to measure individual distortions in confidence in patients. So that's one line of research we're doing. We're also interested in the flip side of this, once we can have animals do the same behavior as humans, we can study the circuits underlying some of these cognitive dimensions that are important for psychiatry. 


\section{$\$_{\text {CSH\& }}^{\infty}$ Cold Spring Harbor Symposia SYMPOSIA On Quantitative Biology}

\section{A Conversation with Adam Kepecs}

Cold Spring Harb Symp Quant Biol 2018 83: 258-260 originally published online June 11, 2019 Access the most recent version at doi:10.1101/sqb.2018.83.038133

Creative This article is distributed under the terms of the

Commons http://creativecommons.org/licenses/by-nc/4.0/, which permits reuse and

License redistribution, except for commercial purposes, provided that the original author and source are credited.

Email Alerting Receive free email alerts when new articles cite this article - sign up in Service the box at the top right corner of the article or click here. 